\title{
PERHITUNGAN VaR PORTOFOLIO SAHAM MENGGUNAKAN DATA HISTORIS DAN DATA SIMULASI MONTE CARLO
}

\author{
WAYAN ARTHINI ${ }^{1}$, KOMANG DHARMAWAN ${ }^{2}$, LUH PUTU IDA HARINI ${ }^{3}$ \\ ${ }^{1,2,3}$ Jurusan Matematika FMIPA Universtitas Udayana, Bukit Jimbaran 80361, \\ e-mail: ${ }^{1}$ Dharmawan.Komang@gmail.com, ${ }^{2}$ ballidah@gmail.com, \\ 3 ar_tutiet@yahoo.com
}

\begin{abstract}
Value at Risk (VaR) is the maximum potential loss on a portfolio based on the probability at a certain time. In this research, portfolio VaR values calculated from historical data and Monte Carlo simulation data. Historical data is processed so as to obtain stock returns, variance, correlation coefficient, and variance-covariance matrix, then the method of Markowitz sought proportion of each stock fund, and portfolio risk and return portfolio. The data was then simulated by Monte Carlo simulation, Exact Monte Carlo Simulation and Expected Monte Carlo Simulation. Exact Monte Carlo simulation have same returns and standard deviation with historical data, while the Expected Monte Carlo Simulation satistic calculation similar to historical data. The results of this research is the portfolio VaR with time horizon $T=1, T=10, T=22$ and the confidence level of $95 \%$, values obtained VaR between historical data and Monte Carlo simulation data with the method exact and expected. Value of VaR from both Monte Carlo simulation is greater than VaR historical data.
\end{abstract}

Keywords: Value at Risk (VaR), Monte Carlo Simulation, Portofolio, Historical data.

\section{Pendahuluan}

Membentuk sebuah portofolio merupakan usaha memaksimalkan tingkat pengembalian (return) yang diharapkan dari investasi yang dilakukan dengan tingkat risiko tertentu. Alat ukur yang dapat digunakan untuk mengestimasi resiko pasar adalah Value at Risk (VaR). Menurut Best [1] Value at Risk (VaR) adalah metode pengukuran resiko secara statistik yang memperkirakan kerugian maksimum yang mungkin terjadi atas suatu portofolio pada tingkat kepercayaan (level of confidence) tertentu.

Perhitungan VaR portofolio saham menggunakan data historis dan data simulasi Monte Carlo menggunakan metode Markowitz, dimana metode Markowitz mengasumsikan bahwa variansi data saham konstan. Data historis merupakan data yang didapat dari bursa saham yang telah dilaporkan bursa saham kepada masyarakat, sedangkan data simulasi didapatkan dengan mensimulasi 
harga saham untuk memperkirakan harga saham berikutnya. Simulasi Monte Carlo mengasumsikan data berdistribusi normal dan menghendaki percobaan berulang kali dengan pembangkitan bilangan acak sehingga didapatkan nilai random pada probabilitas frekuensi tertentu, yang nantinya akan digunakan sebagai estimasi untuk memprediksi kondisi pergerakan saham di masa mendatang.

Dengan demikian akan diketahui nilai Value at Risk (Var) portofolio saham menggunakan data historis dan data simulasi Monte Carlo dan diketahui perbandingan nilai Value at Risk (Var) portofolio saham menggunakan data historis dan data simulasi Monte Carlo.

\section{Metode Penelitian}

Variabel yang digunakan dalam penelitian ini adalah harga penutupan (close price) empat saham dalam satu tahun, periode Juni 2011-Juni 2012 yang diakses di http:www.finance.yahoo.com ,yaitu saham Gudang Garam Tbk. (GGRM.JK), saham Kalbe Farma Tbk. (KLBK.JK), saham Semen Gresik (Persero) Tbk. (SMGR.JK), dan saham Telekomunikasi Indonesia (Persero) Tbk. (TLKM.JK).

Data historis dari keempat saham diolah dan dibentuk dalam portofolio menggunakan Metode Markowitz, kemudian data historis disimulasi dengan Simulasi Monte Carlo dengan menggunakan bantuan program Matlab 7.0. Data simulasi juga dibentuk portofolio, kemudian dicari $V a R$ portofolio dari data historis dan data simulasi Monte Carlo.

\section{Hasil dan Pembahasan}

Data saham dari data historis dicari nilai harapan pengembalian (expected return) dan standar deviasi masing-masing saham ,kemudian disimulasikan dengan simulasi Monte carlo dan perhitungannya dilakukan dengan program Matlab 7.0.

Harapan pengembalian (expected return) dapat dihitung dengan rumus:

$$
E(R)=\frac{1}{n} \sum_{t=1}^{n} R_{t}
$$

Rt dapat dihitung dengan formula :

$$
R_{t}=\ln \left(\frac{s_{t}}{s_{t-1}}\right) \text {, untuk } t=1,2, \ldots, n
$$

Dimana $S_{t}$ adalah harga aset pada saat $t$ (diasumsikan diskret) dan $n$ menyatakan jumlah periode observasi data pergerakan harga saham.

Variansi dari tingkat pengembalian (return) sebuah saham dengan sejumlah $\mathrm{n}$ buah data dirumuskan sebagai berikut:

$$
\sigma^{2}=\frac{1}{n} \sum_{t=1}^{n}\left(R_{t}-E(R)\right)^{2}
$$

Standar deviasi dari saham sebagai berikut :

$$
\sigma=\sqrt{\sigma^{2}}
$$


dimana $\sigma^{2}$ merupakan nilai variansi dari tingkat pengembalian suatu aset, $R_{t}$ menyatakan tingkat pengembalian (return) dari suatu aset pada saat $\mathrm{t}$ dan $\sigma$ menyatakan nilai standar deviasi suatu aset.

Simulasi Monte Carlo (dikenal juga dengan Sampling Simulation atau Monte Carlo Sampling Teachnique) pada intinya adalah simulasi yang mengikutsertakan pembangkitan bilangan acak dengan distribusi probabilitas yang dapat diketahui dan ditentukan. Simulasi Monte Carlo dapat dirumuskan sebagai berikut:

$$
S_{t}=S_{0} e^{\left(r-\frac{\sigma_{t}^{n}}{2}\right) \Delta t+\sigma_{t} s \sqrt{\Delta t}}
$$

Dimana harga saham pada waktu $\mathrm{t}=0$ atau $\mathrm{S}_{0}$ merupakan harga saham saat ini.

Tabel 1. Nilai Expected Return Dan Standar Deviasi Data Historis Dan Data Simulasi Monte Carlo

\begin{tabular}{|c|c|c|c|c|c|c|}
\hline Saham & $\begin{array}{c}\mathrm{E}(\mathrm{R}) \\
\text { Historis }\end{array}$ & $\begin{array}{c}\mathrm{E}(\mathrm{R}) \\
\text { "Exact" }\end{array}$ & $\begin{array}{c}\mathrm{E}(\mathrm{R}) \\
\text { "Expected" }\end{array}$ & $\begin{array}{c}\text { Std } \\
\text { Historis }\end{array}$ & $\begin{array}{c}\text { Std } \\
\text { "Exact" }\end{array}$ & $\begin{array}{c}\text { Std } \\
\text { "Expected" }\end{array}$ \\
\hline GGRM & 0.0013 & 0.0013 & 0.0002 & 0.0219 & 0.0219 & 0.0231 \\
\hline KLBF & 0.0004 & 0.0004 & 0.0031 & 0.0213 & 0.0213 & 0.0223 \\
\hline SMGR & 0.0006 & 0.0006 & 0.0022 & 0.0224 & 0.0224 & 0.0241 \\
\hline TLKM & 0.0001 & 0.0001 & 0.0022 & 0.0174 & 0.0174 & 0.0180 \\
\hline
\end{tabular}

Membentuk portofolio saham dengan Metode Markowitz menggunakan bantuan program Matlab 7.0 dengan model :

$$
\text { Minimalkan : } \frac{1}{2} \boldsymbol{X}^{T} \boldsymbol{H} \boldsymbol{X}
$$

Dengan batasan : $\sum_{i=1}^{n} E\left(R_{i}\right) X_{i}=E\left(R_{p}\right) ; \sum_{i=1}^{n} X_{i}=1 \quad$ dan $X_{i} \geq 0$

Dimana $\mathbf{H}$ merupakan matrik Hessian $\mathrm{n} \times \mathrm{n}$ yang isinya nilai variance-covariance dengan $\sigma_{\mathrm{ij}}$ elemen dari matrik $\mathbf{H}$ adalah konstan, sehingga $\sigma_{\mathrm{ij}}=\sigma_{\mathrm{ji}}$ (Hillier and Lieberman [3]).

Tabel 2. Proporsi Dana Masing-Masing Saham

\begin{tabular}{|c|c|c|c|c|}
\hline No. Port & $\mathrm{X}_{1}$ & $\mathrm{X}_{2}$ & $\mathrm{X}_{3}$ & $\mathrm{X}_{4}$ \\
\hline 1 & 0.1926 & 0.1047 & 0.2095 & 0.4932 \\
\hline 2 & 0.2759 & 0.0821 & 0.2068 & 0.4351 \\
\hline 3 & 0.3593 & 0.0595 & 0.2041 & 0.3771 \\
\hline 4 & 0.4427 & 0.0369 & 0.2014 & 0.3190 \\
\hline 5 & 0.5261 & 0.0142 & 0.1987 & 0.2610 \\
\hline 6 & 0.6088 & 0 & 0.1929 & 0.1983 \\
\hline 7 & 0.6903 & 0 & 0.1820 & 0.1276 \\
\hline 8 & 0.7719 & 0 & 0.1711 & 0.0570 \\
\hline 9 & 0.8640 & 0 & 0.1360 & 0 \\
\hline 10 & 1 & 0 & 0 & 0 \\
\hline
\end{tabular}

Berdasarkan proporsi dana pada Tabel 2 maka diperoleh besarnya tingkat pengembalian portofolio (Port Return) dan risiko portofolio (Port Risk) dengan metode Markowitz dengan formula sebagai berikut:

$$
E\left(R_{p}\right)=E\left(R_{1}\right) X_{1}+E\left(R_{2}\right) X_{2}+E\left(R_{3}\right) X_{3}+E\left(R_{4}\right) X_{4}
$$




$$
\begin{aligned}
\sigma_{p}^{2}=X_{1}^{2} \sigma_{1}^{2}+X_{2}^{2} \sigma_{2}^{2}+X_{3}^{2} \sigma_{3}^{2}+X_{4}^{2} \sigma_{4}^{2} & +2 X_{1} X_{2} \sigma_{12}+2 X_{1} X_{3} \sigma_{13}+2 X_{1} X_{4} \sigma_{14} \\
+ & +2 X_{2} X_{3} \sigma_{23}+2 X_{2} X_{4} \sigma_{24}+2 X_{3} X_{4} \sigma_{34}
\end{aligned}
$$

Tabel 3. Port Risk Dan Port Return Data Historis Dan Data Simulasi Monte Carlo

\begin{tabular}{|c|c|c|c|c|c|c|}
\hline $\begin{array}{c}\text { No. } \\
\text { Port }\end{array}$ & $\begin{array}{c}\text { Port Risk } \\
\text { Historis }\end{array}$ & $\begin{array}{c}\text { Port Risk } \\
\text { "Exact" }\end{array}$ & $\begin{array}{c}\text { Port Risk } \\
\text { "Expected" }\end{array}$ & $\begin{array}{c}\text { Port Return } \\
\text { Historis }\end{array}$ & $\begin{array}{c}\text { Port } \\
\text { Return } \\
\text { "Exact" }\end{array}$ & $\begin{array}{c}\text { Port Return } \\
\text { "Expected" }\end{array}$ \\
\hline 1 & 0.0139 & 0.0197 & 0.0207 & 0.0005 & 0.0005 & 0.0018 \\
\hline 2 & 0.0140 & 0.0200 & 0.0210 & 0.0006 & 0.0006 & 0.0016 \\
\hline 3 & 0.0143 & 0.0203 & 0.0213 & 0.0006 & 0.0007 & 0.0014 \\
\hline 4 & 0.0149 & 0.0205 & 0.0216 & 0.0007 & 0.0007 & 0.0012 \\
\hline 5 & 0.0157 & 0.0208 & 0.0219 & 0.0008 & 0.0008 & 0.0009 \\
\hline 6 & 0.0166 & 0.0211 & 0.0223 & 0.0009 & 0.0009 & 0.0007 \\
\hline 7 & 0.0177 & 0.0214 & 0.0226 & 0.0010 & 0.0010 & 0.0005 \\
\hline 8 & 0.0190 & 0.0217 & 0.0230 & 0.0011 & 0.0011 & 0.0003 \\
\hline 9 & 0.0203 & 0.0220 & 0.0232 & 0.0012 & 0.0012 & 0,0001 \\
\hline 10 & 0.0219 & 0.0219 & 0.0231 & 0.0013 & 0.0013 & 0.0002 \\
\hline
\end{tabular}

Dengan menggunakan program Matlab7 dengan tingkat kepercayaan (confidence level) 95\% sehingga $\alpha=5 \%$ dan time horizon 1, 10 dan 22, diperoleh nilai $V a R$ pada Tabel 4 .

Dalam manajemen risiko dikatakan bahwa $V a R$ mampu mengkomunikasikan risiko dengan baik karena $V a R$ dapat mengukur berapa risiko suatu portofolio (Sunaryo [10])

$$
V a R=-Z_{1-\alpha} \sqrt{T \sum_{i=1}^{n} \sum_{j=1}^{n} X_{i} X_{j} \rho_{i j} \sigma_{i} \sigma_{j} \bar{R}_{i} \bar{R}_{j}}
$$

Tabel 4. Value at Risk Portofolio Saham Dengan $\mathrm{T}=1 . \mathrm{T}=10, \mathrm{~T}=22$

\begin{tabular}{|c|c|c|c|c|c|c|c|c|c|}
\hline $\begin{array}{l}\text { No. } \\
\text { Port }\end{array}$ & \multicolumn{3}{|c|}{ VaR Data Historis } & \multicolumn{3}{c|}{$\begin{array}{c}\text { VaR Data Simulasi Monte } \\
\text { Carlo Exact }\end{array}$} & \multicolumn{3}{c|}{$\begin{array}{c}\text { VaR Data Simulasi Monte } \\
\text { Carlo Expected }\end{array}$} \\
\cline { 2 - 11 } & $\mathrm{T}=1$ & $\mathrm{~T}=10$ & $\mathrm{~T}=22$ & $\mathrm{~T}=1$ & $\mathrm{~T}=10$ & $\mathrm{~T}=22$ & $\mathrm{~T}=1$ & $\mathrm{~T}=10$ & $\mathrm{~T}=22$ \\
\hline 1 & 0.0223 & 0.0706 & 0.1048 & 0.0320 & 0.1011 & 0.1500 & 0.0323 & 0.1020 & 0.1513 \\
\hline 2 & 0.0225 & 0.0710 & 0.1053 & 0.0323 & 0.1022 & 0.1516 & 0.0330 & 0.1043 & 0.1547 \\
\hline 3 & 0.0230 & 0.0726 & 0.1077 & 0.0327 & 0.1034 & 0.1533 & 0.0337 & 0.1066 & 0.1581 \\
\hline 4 & 0.0238 & 0.0753 & 0.1117 & 0.0330 & 0.1045 & 0.1550 & 0.0344 & 0.1089 & 0.1615 \\
\hline 5 & 0.0250 & 0.0791 & 0.1173 & 0.0334 & 0.1056 & 0.1567 & 0.0352 & 0.1112 & 0.1649 \\
\hline 6 & 0.0265 & 0.0837 & 0.1242 & 0.0338 & 0.1068 & 0.1585 & 0.0359 & 0.1135 & 0.1684 \\
\hline 7 & 0.0282 & 0.0891 & 0.1322 & 0.0342 & 0.1082 & 0.1604 & 0.0367 & 0.1159 & 0.1719 \\
\hline 8 & 0.0301 & 0.0952 & 0.1412 & 0.0346 & 0.1095 & 0.1624 & 0.0374 & 0.1183 & 0.1755 \\
\hline 9 & 0.0322 & 0.1018 & 0.1510 & 0.0349 & 0.1105 & 0.1638 & 0.0381 & 0.1204 & 0.1785 \\
\hline 10 & 0.0348 & 0.1102 & 0.1634 & 0.0347 & 0.1098 & 0.1629 & 0.0382 & 0.1207 & 0.1790 \\
\hline
\end{tabular}

Nilai VaR dari portofolio data historis, data simulasi Monte Carlo dengan metode Exact maupun metode Expected semakin besar dengan bertambahnya time horizon. Ini disebabkan karena penyimpangan nilai portofolio lebih mungkin didapatkan dengan periode yang panjang daripada periode yang pendek (singkat). 


\section{Kesimpulan}

Berdasarkan hasil dan pembahasan yang telah diuraikan sebelumnya, maka diperoleh kesimpulan sebagai berikut :

1. Nilai $\operatorname{VaR}$ portofolio yang dihasilkan, dengan periode horizon $\mathrm{T}=1, \mathrm{~T}=10$, $\mathrm{T}=22$ dan tingkat kepercayaan $95 \%$ diperoleh nilai $V a R$ yang berbeda antara data historis dan data simulasi Monte Carlo baik dengan metode Exact maupun Expected.

2. Nilai VaR dari simulasi Monte Carlo baik metode Exact maupun metode Expected lebih besar dari $V a R$ data historis, ini disebabkan karena simulasi Monte Carlo melakukan iterasi yang berulang-ulang dengan mengikutsertakan pembangkitan bilangan acak. Nilai VaR dari data simulasi Monte Carlo dengan metode Exact lebih mendekati nilai VaR data historis karena nilai dari expected return dan standar deviasinya sama dengan data historis, sedangkan simulasi Monte Carlo dengan metode Expected distribusi statistiknya yang sama dengan data historis.

\section{Daftar Pustaka}

[1] Best, Philip. 1998. Implementing Value at Risk. John Wiley \& Sons Ltd. England.

[2] Engle, Robert F. dan Simone Manganelli. 2001. "Value at Risk Models in Finance". Working Paper no 75 Europan Central Bank (EBC). Germany.

[3] Hillier, Frederick S. and Gerald J.Lieberman. 1990. Introduction to Operation Research. Fifth Edition. McGraw-Hill International Edition. Singapura.

[4] Husnan, S. 1998. Dasar-dasar Teori Portofolio dan Analisis Sekuritas. Edisi Ketiga. UPP AMP YKPM.Yogyakarta.

[5] Jorion, Philipe. 2002. Value at Risk : a New Benchmark for Managing Financial Risk. McGraw Hill. Singapore.

[6] Markowitz, H. 1952. Portofolio Selection,Journal of Finance, Vol.VII, No.1, pp. 77-91.

[7]Markowitz, H. 1959. Portofolio Selection: Efficient Diversification of Investment. John Wiley \& Sons. New York.

[8] Sartono, Agus R. 2006. Var Portofolio Optimal: Perbandingan Antara Metode Markowitz Dan Mean Absolute Deviation, Vol.11 No.1, hlm 37-50.

[9] Scherer, Bernd and Martin. 2005. Introduction to Modern Portofolio Optimization With NUOPT and S-PLUS. Springer. United State of Amerika.

[10] Sunaryo, T. 2007. Manajemen Risiko Finansial. Salemba Empat. Jakarta. 